\title{
Pengaruh Generativity, Experience Expectation dan Motivation Terhadap Visit Intention Pada Museum Mojopahit Mojokerto
}

\author{
Jeffry Andreanto Ferdian(1) \\ Erna Andajani ${ }^{(2)}$ \\ Siti Rahayu ${ }^{(3)}$ \\ ${ }^{(1)(2)(3)}$ Fakultas Bisnis dan Ekonomika, Universitas Surabaya, Jawa Timur \\ Email: ernajani@staff.ubaya.ac.id

\begin{tabular}{|l|l|l|}
\hline Diterima: 2 Pebruari 2021 & Direvisi: 23 Pebruari 2021 & Disetujui: 27 Pebruari 2021 \\
\hline
\end{tabular}

\begin{abstract}
This research aims to determine the effect of generativity, experience expectation, and motivation on visit intention. The object that we use here is Mojokerto Mojopahit Museum. Data processing was carried out using the IBM SPSS 24 program, in addition, researchers used IBM AMOS 22 which will be used for the SEM method or Structural Equation Model. The data in this study will use primary data obtained from online questionnaires. Respondents in this study were 200 people who have an interest in coming to the Mojopahit Museum in Mojokerto and have a generative nature. Sampling used non-probability sampling techniques and convenience sampling. The results of this study will indicate a significant positive effect of generativity on experience expectation, then experience expectation on motivation, and the influence of motivation on visit intention at the Mojopahit Museum in Mojokerto.
\end{abstract}

Keywords: generativity, experience expectation, motivation, visit intention, museum tourism.

\section{Pendahuluan}

Museum merupakan sebuah tempat yang menampilkan pameran berwujud maupun tidak berwujud yang digunakan untuk tujuan pendidikan ataupun hiburan yang saat ini telah menjadi objek wisata penting di sebuah wilayah (Esteban, 2017). Seperti yang semua tahu bahwa di dalam museum terdapat banyak sekali pengetahuan yang dapat ditemukan, mulai dari pengetahuan sejarah, budaya, pendidikan serta banyak hal lainya yang membantu dalam mendapatkan informasi. Su \& Teng (2018) menyatakan bahwa museum juga memiliki keuntungan ekonomi yang menyumbang lebih dari 50\% dari semua kunjungan wisata budaya. Selain keuntungan ekonomi keberadaan museum di sebuah wilayah juga akan menunjukan tradisi atau budaya -budaya yang berada disekitar wilayah tersebut. Selain keuntungan ekonomi keberadaan museum di sebuah wilayah juga akan menunjukan tradisi atau budaya-budaya yang berada di sekitar wilayah tersebut. Hal ini menjadi sangat penting karena dengan adanya museum akan dapat meningkatkan sektor 
pariwisata suatu wilayah dan juga akan menjadi sumber dari regenerasi mengenai budaya budaya yang ada (Zhang et al., 2017). Semua hal diatas menunjukan bahwa keberadaan museum menjadi suatu hal yang penting bagi suatu wilayah terutama sebuah negara yang memiliki nilai historis yang tinggi, karena dengan memanfaatkan keberadaan museum yang dikelola dengan benar bisa saja akan mendatangkan keuntungan bagi negara tersebut serta dapat mewariskan ilmu dan budaya dari wilayah tersebut kepada wisatawan maupun kepada generasi selanjutnya.

Indonesia yang dikenal akan banyak sekali sejarah mengenai penjajahan Belanda, Jepang dan sejarah mengenai kerajaan kerajaan, membuat beberapa pihak yang peduli akan sejarah tersebut membuat sebuah museum yang digunakan agar masyarakat Indonesia tidak lupa tentang sejarah bangsanya sendiri. Namun jumlah museum di Indonesia masih bisa dibilang kurang dari kata cukup, hal ini dapat dilihat dari perbandingan jumlah penduduk dengan jumlah museum di Indonesia. Penduduk Indonesia pada sensus 2019 menunjukan 269,9 juta orang, sedangkan untuk museum di Indonesia hanya berjumlah 428 museum saja. Hal ini sangat berbanding terbalik dengan kondisi di Amerika Serikat yang memiliki jumlah penduduk sebesar 320 juta orang yang diimbangi juga dengan jumlah museum sebesar 35 ribu museum. Minimnya museum di Indonesia bukan berarti minim akan belajar terhadap pengetahuan sejarah. Pada saat ini banyak juga museum museum yang telah bekerja sama dengan universitas agar dapat memperluas edukasi dari museum tersebut.

Ada beberapa faktor yang dapat mempengaruhi keberlangsungan suatu museum. Salah satunya adalah generativity atau kepedulian terhadap generasi selanjutnya. Generativitas sendiri mengacu pada perhatian individu untuk membangun dan membimbing generasi mendatang (Erikson, 1950). Ketika seseorang memiliki sifat peduli akan generasi selanjutnya maka hal itu akan mempengaruhi keinginannya untuk datang mencari ilmu terkait sejarah maupun budaya yang mungkin nantinya akan diwariskan ke anak cucunya. Secara khusus, sifat generatif dapat membentuk harapan dan motivasi wisatawan, karena pengalaman museum dapat membuka mata dan menginspirasi dan dibagikan dengan orang lain, sehingga memfasilitasi keinginan orang untuk 'membimbing generasi berikutnya' (Erikson, 1950). Beberapa koleksi yang dimiliki oleh Museum Majapahit sangat membantu para sejarawan untuk mendapatkan informasi terkait budaya, sistem perdagangan, pertanian, agama, budaya, arsitektur yang terkait dengan Majapahit, bahkan tidak hanya Majaphit sekarang juga hampir semua terkait budaya hindu budha ada di museum tersebut. Koleksi dari museum ini bisa dibilang cukup lengkap, hal ini bisa dilihat dari koleksi nya seperti koleksi tanah liat atau terakota, koleksi keramik jaman Majapahit, kolesi logam serta koleksi batu 
batu peninggalan. Museum ini juga dilengkapi dengan koleksi fosil binatang dan alat bertahan hidup dari masa prasejarah.

Peneliti melakukan replikasi yang tanpa mengurangi variabel dari jurnal sebelumnya yaitu milik Luo, et al. (2018). Penelitian kali ini menggunakan 4 variabel yang diambil dari jurnal sebelumnya yaitu generativity, experience expectation, motivation dan intention to visit. Dimana variabel tersebut digunakan menganalisis sebuah museum di Trowulan Mojokerto. Dengan banyaknya kesamaan antara objek sebelumnya di kota Makau dengan Kabupaten Mojokerto menjadikan museum Majapahit Trowulan menjadi baik dalam penelitian terkait variabel generativity, experience expectation, motivation dan intention to visit. Tujuan penelitian ini untuk menganalisis pengaruh generativity terhadap experience expectation, motivation dan visit intention pada Museum Mojopahit Mojokerto

\section{Telaah Literatur Dan Kajian Pustaka}

Generativity. Generativitas adalah orientasi individu terhadap kepedulian dan perhatian untuk generasi mendatang terkait dengan pemberian pengetahuan warisan untuk regenerasi Erikson (1950). Lawford, et al. (2005) menyelidiki bahwa konstruksi dari generativitas terkait sebuah konsep mengenai kepedulian dan perhatian untuk generasi berikutnya, yang secara tradisional dipandang penting bagi orang dewasa paruh baya untuk mengedukasi yang lain. Generativitas sendiri bukanlah sebuah konsep yang stagnan tetapi ide perkembangan yang dinamis, dengan demikian akan memungkinkan untuk berubah dan berkembang seiring dengan pertumbuhan masyarakat (Erikson, 1950). Penuturan dari beberapa ahli tersebut menunjukan bahwa seiring bertambahnya usia, maka akan timbul perasaan kepedulian untuk menyampaikan kekhawatiran serta mengambil tindakan demi generasi mendatang. McAdams \& de St Aubin (1992) menjelaskan bahwa, generatif adalah orang yang menciptakan, memelihara, dan mewariskan warisan yang ada kepada generasi berikutnya. Dari hal di atas disimpulkan bahwa generativity dapat diukur dengan beberapa indikator seperti : 1) Kontribusi seseorang terhadap kepedulian wilayahnya, 2) Percaya bahwa apa yang di bagikan terkait hal yang didapatkan di Museum akan diingat oleh orang lain, 3) Memiliki rasa tanggung jawab akan generasi selanjutnya, 4) Memilki sifat proaktif 5) memiliki pengetahuan yang akan disebarkan.

Motivation. Motivasi adalah penentu utama perilaku wisatawan, karena dianggap sebagai pendorong perilaku manusia dan faktor penjelas untuk aspek tertentu yang terkait dengan kegiatan wisata (Smith \& Costello, 2009). Motivasi berasal dari keadaan batin, kebutuhan dan keinginan orang dan membujuk mereka untuk melakukan atau terus melakukan perilaku tertentu (Decrop, 2006). Motivasi sendiri merupakan sebuah variabel yang penting bagi konsumen dalam 
menjalankan atau berminat dalam melakukan seseuatu termasuk didalamnya memilih untuk mengunjungi suatu objek. para sarjana pariwisata telah mengembangkan teori untuk memahami motivasi wisatawan. Ryan \& Glendon (1998) mengidentifikasi empat dimensi motivasi, yaitu sosial, relaksasi, intelektual dan penguasaan kompetensi. Berikut indikator dalam pengukuran variabel motivation : 1.) Memiliki kemauan terkait menghadirkan topik pembicaraan yang lebih menarik terkait hal yang didapat di Museum, 2) Memiliki kemauan untuk meningkatkan personal value dari yang didapatkan dari Museum, 3) Memiliki kemauan untuk mendapatkan pengalaman bahagia di Museum, 4) Memiliki kemauan untuk mengedukasi genarsi selanjutnya terkait hal yang ada di Museum.

Experience Expectation. Experience expectation adalah persepsi sebelum mengalami produk atau atribut yang terbentuk sebelumnya melalui pengalaman pencarian (Fallon, 2008). Ekspetasi juga mengacu pada tingkat keyakinan bahwa suatu tindakan akan diikuti oleh konsekuensi tertentu (Feather, 1992). Ekspetasi itu penting, karena evaluasi produk yang sesuai dibentuk dari keyakinan yang terbentuk sebelumnya (Fallon, 2008). Dalam pariwisata, ekspektasi sangat penting ketika wisatawan mempertimbangkan untuk bergabung dengan kegiatan pariwisata atau mengunjungi tujuan (Andereck et al., 2012). Selain itu pengalaman seseorang juga dapat mempengaruhi ekspetasi seseorang terhadap suatu tempat. Hal ini dapat dipengaruhi melalui banyak hal, salah satunya ada word of mouth (WOM). Menurut Zeithaml, et al. (1993) menyatakan bahwa ekspektasi layanan (yaitu layanan yang diinginkan dan diprediksi) dipengaruhi oleh pengalaman pelanggan sebelumnya, dari mulut ke mulut (WOM) dan janji layanan implisit dan eksplisit. Dari hal diatas menujukan bahwa expected experience dapat diukur melalui beberapa indikator seperti : 1) Memiliki harapan untuk menemukan sesuatu yang menarik di museum, 2) Memiliki harapan untuk melihat karakteristik dari suatu budaya di museum, 3) Memiliki harapan untuk dapat merasakan objek fisik dari budaya yang ada di museum.

Visit Intention. Visit intention adalah kemungkinan wisatawan benar-benar mengunjungi tujuan tertentu (Ahn et al., 2013). Niat kunjungan adalah kombinasi minat konsumen dan kemungkinan mengunjungi suatu tempat. Menurut Beerli \& Martin (2004) menunjukkan bahwa sikap dan preferensi orang mempengaruhi niat berkunjung mereka. Bian dan Forsythe (2012) menunjukkan bahwa ciri-ciri pribadi, seperti kebutuhan konsumen akan keunikan dan pemantauan diri, mempengaruhi niat perilaku individu dan mengasumsikan bahwa sifat memiliki dampak langsung pada niat mengenai suatu perilaku. Pengukuran skala mengenai variabel ini didasari dari Ahn, et al (2013) dan Baker \& Crompton (2000). Berikut beberapa indikator terkait pengukuran variabel 
visit intention : 1) Kemungkinan mengunjungi Museum tinggi, 2) kemauan seseorang ketika memiliki waktu luang untuk datang ke Museum, 3) Memiliki minat untuk berkunjung ke Museum. Berdasarkan uraian di atas tersebut, maka muncul hipotesa seperti berikut:

H1: Generativity memiliki pengaruh positif terhadap experience expectation

H2: Generativity memiliki pengaruh positif terhadap motivation

H3: Generativity memiliki pengaruh positif terhadap visit intention

H4: Motivation memiliki pengaruh positif pada visit intention

H5: Experiencen expectation memiliki pengaruh positif pada motivation

H6: Experience expectation memiliki pengaruh positif terhadap visit intention

\section{Metode Penelitian}

Penelitian ini menggunakan penelitian jenis kausal. Data yang digunakan pada penelitian ini adalah data primer dengan cara menyebarkan kuesioner. Jumlah sampel dalam penelitian ini akan ditetapkan sebesar 200 orang (Hair, et al., 2010). Data yang didapat akan diolah menggunakan AMOS. Pengambilan sampel menggunakan teknik non probability sampling dan convenience sampling. Teknik ini melihatkan bahwa probabilitas setiap populasi tidak akan sama dalam menjadi sampel. Convenience sampling digunakan karena mudah dalam pendapatan data, proses cepat serta memiliki hasil yang akurat dari jumlah populasi yang dipilih.

\section{Hasil Dan Pembahasan}

Hasil uji validitas dan reliabilitas terlihat pada tabel berikut:

Tabel 1. Uji Validitas dan Reliabilitas

\begin{tabular}{|c|c|c|c|c|c|}
\hline Variabel & $\begin{array}{l}\text { Pearson } \\
\text { Cor. }\end{array}$ & Sig & Ket & $\begin{array}{l}\text { Cronbanch } \\
\text { Alpha }\end{array}$ & Ket. \\
\hline \multicolumn{6}{|l|}{ Genrativity (Contribution) } \\
\hline $\begin{array}{l}\text { Saya memiliki tanggung jawab untuk } \\
\text { menginkatkan lingkungan tempat saya } \\
\text { tinggal }\end{array}$ & 0.838 & ,000 & Valid & 0.790 & Reliabel \\
\hline $\begin{array}{l}\text { Saya akan memberikan pengetahuan yang } \\
\text { saya dapatkan di Museum Mojopahit } \\
\text { Mojokerto pada orang lain }\end{array}$ & 0.862 & ,000 & Valid & & \\
\hline $\begin{array}{l}\text { Kontribusi pengetahuan yang saya berikan } \\
\text { dapat tetap dikenang ketika Saya telah } \\
\text { tiada }\end{array}$ & 0.839 & ,000 & Valid & & \\
\hline \multicolumn{6}{|l|}{ Generativity (Remebered) } \\
\hline $\begin{array}{l}\text { Saya telah memberikan kontribusi yang } \\
\text { berdampak bagi orang lain }\end{array}$ & 0.758 &, 000 & Valid & 0.735 & Reliabel \\
\hline $\begin{array}{l}\text { Saya telah memberi kontribusi } \\
\text { pengetahuan yang dapat dikenang ketika } \\
\text { saya meninggal }\end{array}$ & 0.846 & 000 & Valid & & \\
\hline
\end{tabular}


Saya mendengar orang lain mengatakan bahwa Saya meberikan kontribusi yang positif

Tindakan Saya dalam menyebarkan pengetahuan tidak berdampak positif pada orang lain

\section{Generativity (Creativity)}

Saya merupakan orang yang kreatif dalam banyak hal yang saya lakukan

Saya mendengar orang lain mengatakan bahwa saya adalah orang yang aktif

Generativity (Responsibility)

Saya telah membuat banyak komitmen kepada berbagai jenis orang, kelompok, dan aktivitas dalam hidup saya.

Saya merasa orang lain membutuhkan saya.

\section{Generativity (Knowledge)}

Saya berusaha menyebarkan pengalaman

Saya sebagai pengetahuan kepada orang lain.

Saya berusaha menyebarkan pengalaman Saya sebagai pengetahuan kepada orang lain.

\section{Experience Expectation}

Saya dapat menemukan hal menarik di

Museum Majapahit di Mojokerto

Saya dapat melihat karakteristik budaya

lokal di Museum Majapahit di Mojokerto

Saya dapat melihat objek fisik

peninggalan sejarah budaya lokal ketika mengunjungi Museum Majapahit di

Mojokerto

\section{Motivation}

Saya merasa dapat menemukan topik pembahasan yang menarik untuk percakapan di Museum Majapahit Mojokerto

Saya merasa dapat meningkatkan personal value dalam hal pengetahuan di Museum Majapahit Mojokerto

Saya merasa dapat mendapatkan pengalaman yang membahagiakan di Museum Majapahit Mojokerto

\section{Visit intention}

Saya memiliki keinginan yang kuat untuk datang ke museum Majapahit Mojokerto Jika saya punya waktu, saya akan mengunjungi Museum Majapahit Mojokerto.

\author{
$0.772,000$ Valid \\ $0.673,000$ Valid
}

$0.878 \quad, 000$ Valid

0.713 Reliabel

$0.884 \quad, 000$ Valid

$0.881 \quad, 000$ Valid

0.702 Reliabel

$0.875 \quad, 000$ Valid

$0.905 \quad, 000$ Valid

0.808 Reliabel

$0.930 \quad, 000$ Valid

$0.771 \quad, 000$ Valid

$0.720 \quad$ Reliabel

$0.821 \quad, 000$ Valid

$0.826 \quad, 000$ Valid

$0.848 \quad, 000$ Valid

0.741 Reliabel

$0.750 \quad, 000$ Valid

$0.849,000$ Valid

$0.812,000$ Valid

0.808 Reliabel

$0.869,000$ Valid 
Saya memiliki niat untuk mengunjungi

0.870

,000 Valid

Museum Majapahit Mojokerto.

Pengujian model pengukuran (Measurement Model) dalam penelitian ini diperoleh dari hasil pengolahan pada software AMOS 22. Hasil pengukuran yaitu CMIN/DF 1,936 (Good fit), RMSEA 0,069 (Good fit), GFI 0.845 (Marginal fit), TLI 0.918 (Good fit) dan CFI 0.928 (Good fit). Pada tahap selanjutnya dilakukan pengujian model struktural. Adapun hasil pengukuran yaitu CMIN/DF 1,936 (Good fit), RMSEA 0,069 (Good fit), GFI 0.845 (Marginal fit), TLI 0.918 (Good fit) dan CFI 0.928 (Good fit).

Pengujian hipotesis ini memiliki tolak ukur dari probabilitas dan critical ration (CR). Probabilitas disini digunakan untuk mengetahui suatu variabel dikatakan signifikan atau tidak, dimana standart untuk valid adalah $\mathrm{P} \leq 0.05$. Critical ratio memiliki fungsi sebagai penentu sebuah hipotesa terdukung atau tidak terdukung. Jika nilai dari $C R \geq 1.96$ maka dapat dikatakan hipotesa terebut terdukung. Berikut hasil pengolahan data uji hipotesis

\section{Tabel 2. Hasil Uji Hipotesis}

\begin{tabular}{|c|c|c|c|c|c|}
\hline Hipotesis & Path & $\begin{array}{c}\text { Std } \\
\text { Estimates }\end{array}$ & C.R. & $\mathrm{P}$ & Keterangan \\
\hline $\mathrm{H} 1(+)$ & $\begin{array}{c}\text { Generativity > Experience } \\
\text { Expectation }\end{array}$ & 0.417 & 6.493 & $* * *$ & H1 Terdukung \\
\hline $\mathrm{H} 2(+)$ & Generativity > Motivation & 0.100 & 1.464 & 0.143 & H2 Tidak Terdukung \\
\hline $\mathrm{H} 3(+)$ & Generativity > Visit Intention & -0.008 & -0.083 & 0.934 & H3 Tidak Terdukung \\
\hline $\mathrm{H} 4(+)$ & Motivation > Visit Intenttion & 1.503 & 2.810 & 0.005 & H4 Terdukung \\
\hline $\mathrm{H} 5(+)$ & $\begin{array}{c}\text { Experience Expectation > } \\
\text { Motivation }\end{array}$ & 1.094 & 8.619 & $* * *$ & H5 Terdukung \\
\hline H6 (+) & $\begin{array}{c}\text { Experience Expectation > Visit } \\
\text { Intention }\end{array}$ & -0.773 & -1.229 & 0.219 & H6 Tidak Terdukung \\
\hline
\end{tabular}

Penelitian ini menunjukan bahwa hipotesis pertama memiliki hubungan yang terdukung dan signifikan. Hipotesis ini sesuai dengan penelitian sebelumnya yang dilakukan oleh Luo, et al. (2018) yang juga menunjukan adanya hasil dari pengaruh generativity dan experience expectation. Hal ini menunjukan semakin tinggi sifat atau karakter generatif seseorang akan menambah keinginan mereka untuk mencari tau terkait objek sehingga akan membentuk experience expectation. Dari penjelasan diatas menunjukan bahwa nilai-nilai yang dimiliki oleh responden akan dapat berkontribusi pada pra pengelaman wisatawan. Nilai-nilai seperti generativity yang memiliki kepedulian akan generasi mendatang, akan menambaha kontribusi terhadap experience expectation, dimana hal ini juga telah sesuai dengan faktor-faktor hasil penelitian Sheng \& Chen (2012), yang menunjukan bahwa ketertarikan akan cultural entertaiment serta historical reminisence akan berkontribusi terhadap experience expectation. Seseorang dengan generativity yang tinggi akan menyebarkan pengalaman dan pengetahuan terkait sejarah serta budaya di 
Museum Mojopahit Mojokerto kepada orang lain. Dimana hal ini juga telah sesuai dengan penelitian yang telah dilakukan oleh Luo, et al. (2018) yang menunjukan adanya keterkaitan antara kedua variabel tersebut.

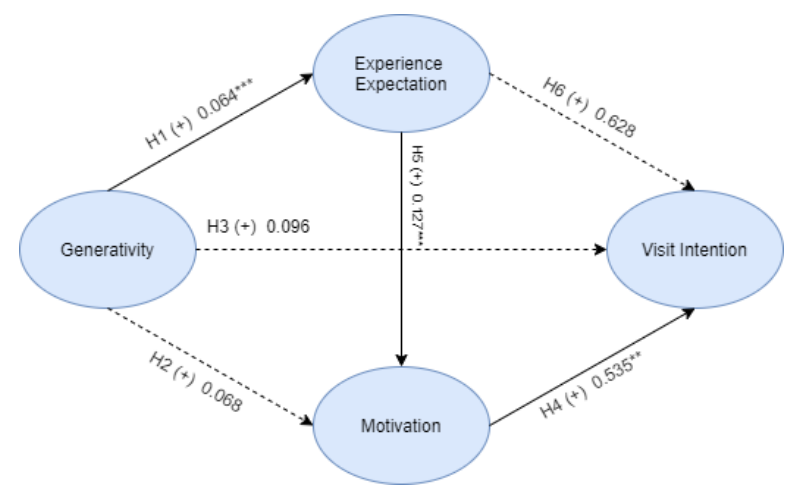

Gambar 1. Model Penelitian

Hipotesis kedua dan ketiga akan membahas mengenai pengaruh generativity, motivation dan visit intention. Dimana dalam penelitian ini menunjukan bahwa hipotesis kedua tidak terdukung dan tidak signifikan. Museum masih perlu untuk meningkatkan kegiatan yang menarik motivasi pengunjung yang terkait dengan kontek generativity. Hal ini meliputi materi, informasi dan beberapa koleksi yang dipamerkan. Secara tidak langsung dapat dikatakan bahwa motivasi akan terbentuk ketika wisatawan telah mendapatkan informasi dan latar belakang yang jelas terkait museum tersebut, dimana artinya wisatawan akan membutuhkan pra pengalaman untuk memicu adanya motivasi tersebut. Sedangkan bisa diketahui bahwa minat kunjungan wisatawan ke sebuah museum masih kurang. Banyak hal seperti kurangnya informasi dan promosi terkait Museum, tempat yang susah dijangkau serta bangunan yang identik dengan desain kuno membuat Museum tidak lagi diminati (Kompasiana.com, diakses 1 November 2020).

Hipotesis keempat akan membahas mengenai pengaruh motivation dan visit intention. Penelitian yang dilakukan oleh Beerli-Palacio, et al. (2017) menunjukan bahwa terdapat 3 faktor yang dapat menjadi pengukur akan motivasi seseorang. Dimana terdapat 2 faktor yang berkaitan dengan hipotesa ini, yaitu intelektual dan escape. Intelektual dan escape yang dimaksud disini adalah keinginan untuk mengetahui sejarah suatu negara, mengalami budaya dan gaya hidup yang berbeda di tempat tujuan, menemukan lingkungan alam, meningkatkan pengetahuan tentang suatu tempat, orang, atau benda. Hal ini menunjukan bahwa ketika seseorang memiliki keinginan untuk mempelajari sejarah atau budaya dapat memicu motivasi wisatawan dalam menentukan tujuan wisatanya. 
Selain itu pada hipotesis ke 5, dimana dalam penelitian ini menunjukan bahwa hipotesis kelima memiliki hubungan yang terdukung dan signifikan. Penelitian dari Rivera, et al. (2015) menunjukan bahwa ketika seseorang melakukan pencarian informasi yang dipublikasikan di blog, jejaring sosial, dan platform untuk layanan berbagi mulai memberikan pengaruh dalam motivasi untuk mengunjungi suatu tempat. Ketika seseorang telah memiliki ekspektasi berdasarkan informasi yang telah dicari maka akan membuat motivasi seseorang semakin besar untuk mengunjungi hal itu.

Hipotesis keenam akan membahas mengenai pengaruh experience expectation terhadap visit intention. Dimana dalam penelitian ini menunjukan bahwa hipotesis keenam tidak terdukung dan tidak signifikan. Hal ini dapat terjadi karena secara tidak langsung menunjukan bahwa pra pengelaman yang didapatkan wisatawan melalui internet atau pengalaman seseorang tidak dapat mendorong seseorang untuk datang ke Museum, karena persepsi masyarakat indonesia yang beranggapan museum merupakan tempat yang kuno, panas dan membosankan (Wibowo, 2015).

\section{Simpulan}

Penelitian menunjukan 3 hipotesa terdukung dan 3 hipotesa yang lain tidak terdukung. Hipotesa yang terdukung memperlihatkan adanya hubungan antar variabel generativity terhadap experience expectation, experience expectation terhadap motivation, lalu yang terakir motivation terhadap visit intention. Dimana terdapat juga 3 hipotesa yang tidak terdukung yaitu generativity terhadap motivation, generativity terhadap visit intention, lalu yang terakir adalah experience expectation terhadap motivation.

Penelitian melakukan replikasi sesuai dengan jurnal penelitian karya Luo, et al (2018). Sehingga hal tersebut membuat perlunya pengkajian kembali, karena objek yang diteliti memiliki perbedaan wisatawan, ekonomi dan budaya. Pada penelitian ini terdapat beberapa hipotesa yang tidak terdukung. Sehingga perbedaan tersebut bisa saja menjadi penyebab bedanya hasil penelitian.

\section{Daftar Pustaka}

Ahn, Ekinci, \& Li. 2013. Self-congruence, functional congruence, and destination choice. Journal of Business Research, 719-723.

Andereck, K., McGehee, N. G., Lee, S., \& Clemmons, D. 2012. Experience expectations of prospective volunteer tourists. Journal of Travel Research, 51(2), 130-141

Baker, D. A., \& Crompton, J. L. 2000. Quality, satisfaction and behavioral intentions. Annals of Tourism Research, 27(3), 785-804.

Beerli, A., \& Martin, J. D. 2004. Factors influencing destination image. Annals of Tourism Research, 31(3), 657-681.

Beerli-Palacio, A Josefa D. \& Martín-Santana. 2017. How does confirmation of motivations influence on the pre- and post-visit change of image of a destination?. European Journal of 
Management and Business Economics, Vol. 26 Issue: 2: 238-251. https://doi.org/10.1108/ EJMBE-07-2017-014

Bian, Q., \& Forsythe, S. 2012. Purchase intention for luxury brands: A cross cultural comparison. Journal of Business Research, 65(10), 1443-1451

Decrop, A. (n.d.). 2006. Vacation decision-making. CABI-Publishing, Wallingford.

Erikson, E. 1950. Major stages in psychosocial development. The life cycle completed. New York: Rikan Enterprises Ltd.Erikson, E. 1963 . Childhood and society (2nd ed.). New York, NY: W. W. Norton.

Esteban, N. R. R. 2017. A management guide for university museums focused in the cultural tourism-the case of the "Museo de Arte De La Universidad Nacional" Tourismos: An International Multidisciplinary Journal of Tourism, 12(1), 21-56

Fallon, P. 2008. Monitoring visitor satisfaction with destinations using expectations, importance and performance constructs. Tourism Management Analysis, Behaviour and Strategy, 242458.

Feather, N. 1992. Values, valences, expectations, and actions. Journal of Social Issues, 109-124.

Hair, J. F., Black, W. C., \& Babin, B. J. (2010). Multivariate dataanalysis (7th ed.). Prentice Hall, Upper Saddle River.

Lawford, H., Pratt, M. W., Hunsberger, B., \& Mark Pancer, S. 2005. Adolescent generativity: A longitudinal study of two possible contexts for learning concern for future generations. Journal of Research on Adolescence, 15(3), 261-273.

Luo, J. M., Lam, C. F., \& Fan, D. X. 2018. The development of measurement scale for entertainment tourism experience: A case study in Macau. Current Issues in Tourism, 1-15. https://doi.org/10.1080/13683500.2018.1556251.

McAdams, D. P., \& de St Aubin, E. D. 1992. A theory of generativity and its assessment through self-report, behavioral acts, and narrative themes in autobiography. Journal of Personality and Social Psychology, 62(6), 1003-1015.

Rivera, J. C., Di Gangi, P. M., Worrell, J. L., Thompson, S. C., \& Johnston, A. C. 2015. Undergraduate student perceptions of personal social media risk. Information Security Education Journal, 2(2), 49-56.

Sheng, C. W., \& Chen, M. C. (2012). A study of experience expectations of museum visitors. Tourism Management, 33(1), 53-60.

Smith, S., \& Costello, C. 2009. Segmenting visitors to a culinary event: Motivations, travel behavior, and expenditures. Journal of Hospitality Marketing \& Management, 18(1), 44-67.

$\mathrm{Su}, \mathrm{Y} .$, \& Teng, W. 2018. Contemplating museums' service failure: Extracting the service quality dimensions of museums from negative on-line reviews. Tourism Management, 69, 214-222.

Ryan, C., \& Glendon, I. 1998. Application of leisure motivation scale to tourism. Annals of Tourism Research, 25(1), 169-184.

Wibowo, A. (2015). Persepsi Kualitas Layanan Museum di Indonesia: Sebuah Studi Observasi. Jurnal Manajemen Maranatha, 15(1). https://doi.org/10.28932/jmm.v15i1.24

Zeithaml, V. A. 1993. The Nature and Determinants of Customer Expectations of Service. Journal of the Academy of Marketing Science, 1-12.

Zhang, H. M., Xu, F. F., Lu, L., \& Yu, P. 2017. The spatial agglomeration of museums, a case study in London. Journal of Heritage Tourism, 12(2), 172-190 